\title{
El naturalismo frente a la fenomenología.
}

Edmund HusserIs, im Jahre seines Todes, gewidmet.

La obra de Edmundo Husserl (1859-1938) inicia una dirección filosófica de importancia capital en el ambiente cultural de nuestro siglo. Realizada con genial hondura y con una austeridad y una prudencia casi sin pares en la historia de la filosofía, la obra de Husserl ha abierto nuevos horizontes a esta disciplina, que amenazaba involucionar, después de la evolución grandiosa a la que la había empujado la revolución kantiana, precisamente por haberse agotado los motivos impulsores que se habían agitado, señeros, en las Críticas. Sobre la importancia de la fenomenología como dirección filosófica del presente, dicen mucho los numerosos trabajos realmente llevados a cabo bajo la inspiración de su método. Y, sobre todo, las figuras filosóficas que le han acordado su adhesión, y cuyas obras de gran estilo están llamadas a estructurar las bases de la filosofía del sigl o XX.

A fines de la pasada centuria, la prosperity (a la cual Husserl hace una referencia amarga en el último de sus escritos aparecidos) había despojado a la filosofía de 
toda influencia sobre la vida, y determinado la ascensión de las diversas ciencias particulares al rango primero en la escala de los valores culturales. "La ciencia mecánico natural, la ciencia positiva, era la disciplina dominante en los espíritus" ( I). Esta situación planteaba el problema del derecho a la existencia de la filosofía. Un camino fué el emprendido por Wundt; a saber, la reunión de los resultados de todas las ciencias particulares en una concepción del mundo. Otro, el reducir la filosofía a teoría del conocimiento; esta fué la tendencia que cobró mayor auge. No menor fué, sin embargo, el alcanzado por el positivismo, que bajo los títulos de empiriocriticismo o positivismo a secas, pretendió, apoyándose en Berkeley, dar una forma sublimada al realismo ingenuo. Otras corrientes, por su lado, concebían la lógica como una mera psicología del pensar, y pretendían que, en último término, la filosofía era identificable con la psicología. Finalmente, gracias a Nietzsche, Dilthey y Eucken, adquirian pujante importancia las disciplinas del espíritu, y, con ellas, el historicismo En este ambiente, desorientado y dispar, aparece la obra de Edmundo Husserl. El punto de partida de esta obra es un ataque dirigido contra el positivismo y el psicologismo dominantes.

La influencia de las Investigaciones Lógicas se extiende rápidamente. La razón de su rápido apogeo reside, seguramente, en la fatiga que había llegado a producir el neokantismo. Como es sabido, el neokantismo ponía la doctrina del conocimiento delante de la doctrina del ser. Esta preponderancia de la teoría del conocimiento trajo como consecuencia una acentuación de los problemas metodológicos y de la importancia misma del método. El pensamien-

(1) Ueberweg, Grundriss der Geschichte der Philosophie. Vierter Teil. Berlín, 1923. 
to central de la escuela de Marburgo se refería a la unidad del método en la progresiva logización de lo "dado". El punto cardinal de la meditación de Rickert era la separación entre ciencia cultural y ciencia natural, y la unión de ambas en un conocimiento determinado por las normas lógicas y por la aspiración al valor de la verdad. La fenomenología, en cambio, venía a aseverar que todo conocimiento es una "mirada" hacia la cosa y que debe estar siempre orientado hacia la cosa.

En el presente trabajo nos proponemos examinar las ideas expuestas por Husserl en la primera parte de un largo artículo aparecido en la revista Logos (I), en el cual completa y desarrolla el ataque contra el naturalismo que había emprendido en los Prolegómenos a las Investigaciones Lógicas. En algunos pasajes hemos debido incursionar en principios fenomenológicos no contenidos en el texto mismo del artículo mencionado, a fin de establecer conexiones de carácter general con la doctrina fenomenológica. En otros, en cambio; soslayamos ideas que hemos debido dar por conocidas. Dada la vastedad de la filosofía fenomenológica, creemos que es inutil empeño intentar aprehenderla dentro del marco reducido de un artículo de revista. Examinemos sólo un problema muy determinado, muy limitado. Valga nuestro examen como una forma de homenaje a la figura ilustre del pensador, a cuya obra relicta nos aproximamos con veneración.

La historia de la filosofía muestra cómo esta disciplina ha pretendido, desde sus comienzos, valer como ciencia ri-

(1) Irogos. Tübingen, 1911. 
gurosa. Ciencia rigurosa, es decir, ciencia capaz de satisfacer las más altas exigencias teoréticas, y de ser apta, en un sentido ético religioso, para brindar las normas racionales puras que hagan posible una vida que igualmente satisfaga las más altas exigencias prácticas. La filosofía no ha declinado nunca esta pretensión de rigurosidad, ni aún durante aquellos períodos en que intereses extraños-religiosos o de otra índole-interfirieron el curso libre de la investigación teorética. A pesar de lo cual la filosofía no ha logrado satisfacer en ninguna época de su desarrollo esta su pretensión original. Desde el Renacimiento hasta el presente, la filosofía ha buscado su camino como ciencia rigurosa, o, para decirlo con el giro kantiano acogido por Husserl en las Investigaciones, "el camino seguro de la ciencia", a través de reflexiones críticas y de investigaciones metódicas severas; reflexiones e investigaciones que estampan su impronta indeclinable en la filosofía de los tiempos modernos, hasta el punto de constituir, aquéllas, el ethos dominante del pensamiento filosófico de la época que preparó el advenimiento de Kant, y, también, el de la época poskantiana hasta nuestros dias. Tampoco estos esfuerzos han logrado dotar a la filosofía del carácter de ciencia rigurosa. El único fin realmente logrado por ellos ha sido la fundamentación de las ciencias estrictas de la naturaleza y del espíritu, así como la de las disciplinas matemáticas puras.

La filosofía, pues, parece estar imposibilitada para alcanzar la estructura de una ciencia que verdaderamente puede ser considerada tal. En principio, toda ciencia puede aprenderse y enseñarse; el tejido total de principios, y cada uno de los principios en sí considerados, de las ciencias, muéstrase siempre y para todos en un sentido cuya univocidad impone en el espíritu de los sabios ideas "claras y defi- 
nidas", pensamientos cuya unidad lógica y epistemológica no se destruye por el hecho de ser aprehendidos por una multitud siempre creciente de individuos. Es precisamente esta firmeza lógica, este valer en sí de los pensamientos, la condición que hace posible sean trasmitidos incólumes en su pureza contextual de maestro a discípulo y de generación a generación. Muy otra cosa sucede con la filosofía. Kant gustaba decir que la filosofía no puede enseñarse; únicamente puede enseñarse a filosofar. $Y$ si la filosofía no puede enseñarse - dice Husserl- es porque en ella falta aquel modo objetivo de discurrir que procede a través de intelecciones que van de fundamento a consecuencia; y también, porque le falta haber delimitado y llevado a completa claridad de sentido, sus problemas, métodos y teorías. O, para hablar con el lenguaje de las Investigaciones Lógicas, en la filosofía han faltado fundamentaciones del tipo de aquellas que hacen posible las ciencias, a saber, fundamentaciones caracterizadas por su acuerdo con formas universales de fundannentación, pore la estable complejidad de sus contenidos $\mathrm{y}_{\text {"por la }}$ "pureza" cque les otorga independencia esencial con respecto a esta o aquella esfera del saber. Y, por otro lado, ha faltado también una adecuación intuitiva plena entre el mentar de los problemas, métodos y teorías filosóficas, con la realización intuitiva de estos problemas mismos, de estos mismos métodos y teorías.

La filosofía no es una ciencia que aún no ha alcanzado la perfección, como lo son, por ejemplo, las maravillantes ciencias exactas. Todas las ciencias son, en efecto, imperfectas en un doble sentido: en primer lugar, por cuanto alrededor de ellas se abre un horizonte infinito de problemas innombrados, que no conceden reposo al impulso del conocimiento; en segundo lugar, por cuanto los problemas a los que ya puede considerarse dominios conquistados de in- 
vestigación, muestran todavéa residuos inexplicados que ensombrecen el orden sistemático de las demostraciones y de las teorías. La imperfección de la filosofía es de una índole completamente distinta. La filosofía no es una ciencia que todavía no ha alcanzado la perfección: la filosofía no es todavía una ciencia, todavía no ha emprendido el camino de la ciencia. A diferencia de las ciencias legítimas, toda posición de principio es, en filosofía, cuestión de convicciones individuales, de puntos de vista; hay, pues, hundido en el senu de esta disciplina, un principio virtual de escepticismo, de relativismo.

Se ha agitado reiteradanente, sin embargo, en los íltimos tiempos, lo que se ha dado en llamar "la crisis de las ciencias europeas". Al análisis de esta crisis, análisis emprendido al hilo de un paralelo con la fenomenología, y con el objeto de servir de introducción a la filosofía trascendental, dedicó Husserl un largo ensayo aparecido en la revista Philosophia, dos años antes de su muerte (I). Crisis de una ciencia Bsignificaeque dsa cientificidad, es decir los fundamentos teoréticos usebrell los cualeso reposan sus problemas y sus métodos, se ha tornado insegura y susceptible de ser considerada como interrogación, puesto que del desarrollo efectivo de la ciencia, en las investigaciones y tratados, no alcanza a desprenderse una respuesta que estructure en forma suficiente y legítima el cumplimiento de las condiciones que hacen posible la ciencia en general. En este sentido no puede hablarse seriamente de una crisis de la matemática pura, de las ciencias naturales exactas, ni, tampoco, de las ciencias del espíritu. La cientificidad de estas disciplinas̄ no puede ser puesta en duda. La cuestión se ha planteado, particularmente, con respecto a la Física. Pero,

(1) Philosophia. Vol. 1. Fasc. 1-4. Belgradi, MCMXXXVI. 
en primer lugar, en el período comprendido desde Galileo y Newton hasta Einstein, ¿ha dejado la Física de considerar, como objeto propio que la constituye realidad científica determinada, la medición del universo material? ¿No es la delimitación de un grupo homogéneo de objetos hacia el cual orienta su investigación, aquello que otorga carta de ciudadanía a una ciencia? $Y$, por lo que toca a su legitimidad, ¿no constituyen patrimonio de nuestro saber científico, en forma de juicios evidentes, los principios formulados por Newton? La física, pues, bajo Galileo y Newton, bajo Planck y Einstein, continúa siendo ciencia exacta (I).

Con lo anterior resalta aún más el contraste entre este grupo de ciencias, de cientificidad indiscutible, y la filosofía. En lo que respecta al objeto de la filosofía, un filósofo cuya doctrina se ha movido dentro del círculo de los neokantianos relativistas, Georg Simmel (2), ha establecido que el primero de los problemas filosóficos es, precisamente, la determinación del objeto de la filosofía. Esta determinación es emprendida, en cada caso, desde el punto de vista, según el sistena adoptadoi pon cada filósofo. Nicolai Hartmann habla de una consecuencia de los sistemas, y la opone a la consecuencia de los problemas, de las aporías mismas, de la consideración e investigación de los proble-

(1) Si bien no puede bablarse de una "crisis" de las ciencias en el sentido aludido, ella resalta en cambio cuando se considera cuán intensamente ha remitido su importancia y significación en la vida de la humanidad de nnuestro tiempo. A partir de la segunda mitad del siglo último, la humanidad culta ha levantado su concepcion del mundo íntegramente sobre la base de las ciencias positivas. Ciencias que, urgidas por la "prosperity", han aleanzado un asombroso desarrollo téenico; pero que han permanecido alejadas y ciegas para los problemas humanos decisivos. "Las meras ciencias empiricas-diee Husserl-hacen meros hombres empíricos". El trastocamiento de los valores se hizo particularmente agudo después de la última guerra; las ciencias no pueden decir palabra sobre el círculo de peligro vital que se estrecha en torno a los hombres. En ninguna eiencia so considera el problema del sentido o de la falta de sentido de la existencia humana.

(2) G. Simmel, Hauptprobleme der Philosophie. Berlín, 1927. 
mas mismos considerados como tales (3). Ahora bien. ¿Puede equipararse la cientificidad de las ciencias exactas, donde la consideración de los problemas no está obnubilada por la adopción previa de un punto de vista sistemático, con la filosofía, cuyos problemas no pueden imponer al espíritu investigador una consecuencia fundada en sus propios contenidos, sencillamente porque estos problemas no han mostrado con evidencia sus límites y sentido?

La situación actual de la filosofía invita a reflexionar. La nostalgia de una filosofía auténticamente viviente, como aquella por ejemplo de Descartes, es hoy patente en el espíritu de los filósofos; ella ha conducido al florecimiento de los "renacimientos". Fué precisamente la época anterior a Descartes, el Renacimiento, la que dotó a la humanidad intelectual de la era moderna de un impulso grandioso que aspira a una filosofía y a una ciencia autónomas. Aunque los motivos que empujaron a aquellos tiempos hacia el establecimiento de esta autonomía han dejado de ser preponderantes parảhoósotros, es ecierto, sin embargo, que el ideal de una cultura estructuradasobreciencias y filosofía de base estrictamente esclarecida por fundamentos racionales últimos -ideal divisado por casi todos los grandes pensadores de la era moderna-, lo debemos al Renacimiento.

En los comienzos de la era moderna aparece la "revolución" cartesiana. Todas las revoluciones que nos muestra la historia de la filosofía han estado inspiradas por un decidido radicalismo. Radicalismo que ha consistido en que, a través de reflexiones crítico-sistemáticas sobre las condiciones de la ciencia exacta, han pretendido configurar de modo totalmente nuevo el edificio doctrinario de la filosofía. Esta voluntad - voluntad que, diría Husserl, constitu-

(3) N. Hartmann, Diesseits von Idealismus und Realismus. Berlin, s/a. 
ye el deber ser del meditar filosófico-es patente en la revolución socrático-platónica. Reaparece, con impulso grandioso, en Descartes. La inspiración de la filosofía cartesiana palpita en los sistemas filosóficos de los siglos XVII y XVIII, renovándose con radicalísimo empeño en la Crítica de la Razón de Kant y dominando el filosofar de Fichte. Este período impresionante nos ofrece el espectáculo de esfuerzos orientados hacia los verdadedos comienzos de los problemas filosóficos decisivos y hacia el establecimiento de su método adecuado. La revolución cartesiana, pues, fué realizada en virtud de meditaciones prototípicas; prototípicas en el doble sentido de que ellas son indispensables a todo filósofo que comienza su obra, y, por otro lado, porque únicamente meditaciones de su género pueden dar comienzo legítimo a toda filosofía. (I)

Con el siglo XIX, en cambio, y con la aparición de la filosofía romántica, sobreviene una mutación. El valor absoluto que Hegel atribuye a su método y a su doctrina, hace que su sistema carezça de aquella base que abre la posibilidad a una filosofia cientifficá, avąąer, la crítica de la razón. Y por otro lado, su filosofía - como toda la filosofía romántica en general-ha operado, sobre el impulso que los tiempos posteriores han tendido hacia una ciencia filosófica rigurosa, tanto un debilitamiento como un falseamiento. Debilitamiento, porque ella preparó el advenimiento del historicismo, al consagrar la tesis de la justificación relativa, con respecto a su tiempo, de toda filosofía. Falseamiento, porque sobre ella se levantó la influencia poderosísima del naturalismo.

El estado de división en que hoy se encuentra la filo-

(1) Edmond Husserl.-Meditations Cartēsiennos. Introduction a la $\mathbf{P}$ nomenologie. París, 1931. 
sofía invita a reflexionar, ¿Cuál es el sentido fundamental de toda filosofía verdadera? Husserl se acoge al ejemplo de Descartes. Las Meditaciones, como queda dicho, constituyen un prototipo de indagación filosófica. Hacia ellas se orienta la fenomenología (la que, según declaración de Husserl, podría ser considerada como un neocartesianismo), y busca el punto de partida en el ego cogito puro, como fundamento absoluto de todo conocimiento. $Y$ es indispensable, en verdad, que acometamos esta tarea, pues los más altos intereses de la cultura humana exigen sea cultivada una filosofía estrictamente científica. No es extraña de ninguna manera a nuestro tiempo la fundamentación de la filosofía como ciencia rigurosa. Está viva justamente en medio del naturalismo dominante, porque el naturalismo pretende despojar a la filosofía de su jerarquía de ciencia capaz de dar un fundamento último a todas las ciencias, y, en general, a todos los problemas de la razón y de la realidad. Es necesario, pues, como tarea previa, emprender una crítica del naturalismo ycdel positivismo. El naturalismo proclamó la necesidad de atender únicamente a la experien. cia. Pero ¿cuál es el sentido y los límites de la "experiencia”? ¿Cuál el valor de cada uno de los datos por élla proporcionados? En verdad, el naturalismo finca en fundamentos teoréticos inadmisibles si se les considera desde el punto de vista de los principios; y, desde el lado práctico, representa un serio peligro para nuestra cultura. Es necesario, pues, referirse en primer lugar a la filosofía naturalista, con una crítica fundamental dirigida contra sus fundamentos y sus métodos. 
"El naturalismo - dice Husserl-es un fenómeno que aparece como consecuencia del descubrimiento de la naturaleza, de la naturaleza en el sentido de una unidad del ser espacio temporal regida por las leyes naturales exactas". En virtud de la serie muy numerosa de conocimientos conquistados por las ciencias naturales, fué ampliándose el círculo del naturalismo, y, consiguientemente, el de la idea (sit venia verbis) de la unidad naturalista de la naturaleza. De modo completamente semejante, el "descubrimiento de la historia" y el auge brillante de la pléyade de genios que fundaron, dentro de la inspiración de la escuela histórica (los hermanos Humboldt, Savigny, Niebuhr; Jacobo Grimm, Mommsen, Ranke, Treitschke; y, finalmente Guillermo Dilthey), nuevas disciplinas del espíritu, condujo al historicismo. Actitud filosófica que igualmente cercena la base de una filosofía en sentido estricto, y a la cual es preciso atacar en sus fundamentos, empleando, para ello, argumentos esenciales semejantes a aquellos que Husserl emplea en su polémica contra el naturalisnoLetras

La naturaleza física cese para el naturalista, principio fundamental y exclusivo. Todo lo que es, es ora algo físico que pertenece a la estructura unitaria de la naturaleza física; ora algo psíquico, o, para decirlo con toda claridad, una mera transformación de lo físico, un "hecho concomitante paralelo" de lo físico y sujeto a lo físico. Según Husserl, dos son las notas que caracterizan a todas las formas extremas y consecuentes del materialismo: la naturalización de la conciencia, con inclusión de todas las vivencias intencionales inmanentes, de un lado; y de otro, la naturalización de las ideas, es decir, de todos los ideales absolutos y de las normas.

Consideremos a la lógica formal como el índice ejemplar de toda idealidad. El naturalista estimará que los prin- 


\section{- $\quad-432-$}

cipios lógico formales no valen sino como leyes del pensar, es decir, como leyes naturales (fundadas en la naturaleza de la conciencia pensante). Recordemos aquí, brevemente, la actitud de Husserl en los Prolegómenos a las Investigaciones Lógicas, e intentamos aproximarnos a élla mostrando sus antecedentes, enraizados en la doctrina lógica de su genial maestro Franz Brentano. Si la validez de los principios lógicos no está supeditada al funcionamiento normal de la facultad intelectual humana, ni, en general, condicionada al modo peculiar de alguna conciencia que podría imaginar una dogmática mística (Dios, ángeles o demonios), es preciso entonces conceder que los principios en cuestión significan idealidades, leyes de contenido puro. El desarraigo de estas idealidades de la conciencia que las conoce, he aquí el tema fundamental de toda aquella argumentación que constituyó el "punto de partida de la fenomenología". Toda la cuestión estriba en demostrar que estas idealidades existen realmente y de modo puro. La pureza, la aprioridad, no admite condiciones. Ahora bien. Brentano había afirmado que todos los llamados juicios afirmativos universales son, en verdad, juicios existenciales negativos. El juicio "la suma de los ángulos interiores de un triángulo suma dos rectos", es un juicio negativo, porque él afirma que un triángulo cuyos ángulos interiores sumen más o ménos de $180^{\circ}$, no existe. De donde se saca la conclusión de que los juicios afirmativos universales son juicios cuya verdad puede ser demostrable, evidente de modo mediato, sin que sea necesario para su formulación, presuponer la existencia positiva de los objetos sobre los cuales en aquéllos se predica; es decir, juicios existenciales negativos: el principio, por ejemplo, que enuncia la relación constante pi en los círculos, es válida, aunque no existan realmente círculos. Es sabido cómo, a su vez, Husserl ha demostrado que la negación de las 
"especies", o más propiamente de las "esencias", constituye una "ceguera para las ideas", para la objetividad irreal de las esencjas. Si bien pues los juicios afirmativos universales (los principios lógicos supremos incluídos) son independientes de toda posición existencial, natural, del objetosujeto, su verdad se hace patente, en cambio, en la evidencia que aprehende intuitivamente la irrealidad ideal de las esencias por aquéllos significadas. ¿Cómo puede subsistir, pues, la tesis del psicologismo, a saber que toda aprehensión sea una percepción, interna o externa, de "objetos"? El psicologismo, ya se le ataque en sus fundamentos o en sus consecuencias, es insostenible tanto en la lógica como en la teoría del conocimiento. ¿No envuelve un contrasentido la explicación psicologista de la aprehensión de la idealidad dada en el número 2, por ejemplo? Nó, la aprehensión de esta idealidad no puede darse sino en la intuición correspondiente.

Empero, la separación de objeto del conocimiento y conciencia cognoscente implicaría eleingresoal extremo de signo inverso al psicologismo, a saber, vel sextremo logicista. Precisamente una investigación llevada a cabo con método fenomenológico, nos muestra que todo conocimiento importa un entrar en relación dos términos fundamentales, la conciencia que conoce y el objeto que es conocido (I). Es preciso pues, en el empeño fenomenológico de superación del psicologismo naturalista y del escepticismo que de él se desprende, rechazar la conciencia psicológica como conciencia cognoscente, y esclarecer el fundamento gnoseológico de la conciencia pura y de los modos apodícticos de conciencia en que son dadas las diferentes regiones de objetos. La apo-

(1) N. Hartmann, Grundzüge einer Metaphysijk der Erkenntnis. Berlin, 


\section{- $434-$}

dicticidad de esta conciencia pura nos ha de brindar la base para establecer la filosofía como ciencia rigurosa.

Los últimos párrafos tocan el problema de la conciencia. Como ya se ha dicho, uno de los errores fundamentales del naturalismo, consiste, según Husserl, en la naturalización de la conciencia. Como la conciencia pura es, precisamente, la noción fenomenológica que nos ha de brindar la base para la explicación de las posibilidades de realización de una filosofía en sentido riguroso, establecer los métodos adecuados a los problemas filosóficos, métodos que han de ser los exigidos por su esencia, es preciso dirigir una crítica radical contra el sinsentido que importa la naturalización de la conciencia.

El naturalista considera que la disciplina filosófica exacta por excelencia es la psicología experimental. A esta disciplina nadie podrá negarle el carácter ni el rango de ciencia; élla ha satisfecho el deseo de quienes tan larga y anhelosamente buscaron una psicologia estrictamente científica. Ciencia cuya importancia sobrepasa sus propios dominios, pues en élla han de encontrar - y de hecho han encontrado-su fudamento científico, tanto la lógica como la teoría del conocimiento, la ética, la estética y la pedagogía. Por lo demás, la psicología es, como se comprende de suyo, el fundamento de todas las ciencias del espíritu, incluso el de la metafísica. Pero no, en último término, el preferente, pues también las ciencias físicas naturales desempeñan un papel decisivo en la fundamentación de la teoría naturalista de la realidad.

Contra esta tesis, afirma Husserl: la psicología es una ciencia de hechos, y, como tal, inhábil para proporcionar 
fundamentos a aquellas disciplinas filosóficas cuyo dominio está constituído por principios puros, por leyes de contenido puro (la lógica pura, la axiología pura). Si así fuera, deberíamos aceptar las contradicciones escépticas a las que ya hemos hecho alusión y que fueron combatidas en el tomo primero de las Investigaciones. Debemos decir algunas palabras sobre el psicologismo y el fisicismo en la teoría del conocimiento (a la que separa Husserl de la lógica en tanto que mathesis amiversalis).

Toda ciencia natural está herida, en su punto de parti$\mathrm{da}$, de una irreductible ingenuidad. La ciencia natural, en efecto, aplica su investigación hacia algo que considera dado, dado simplemente en su ser allí, y que ora reposa y se muda en el espacio infinito ora fluye en el tiempo infinito (I). La experiencia que originalmente dona el ser allí de las cosas y las destaca de su oscuro horizonte de realidad indeterminada, es la percepción. Describir estas objetividades en "simples juicios de experiencia", plantearlas de modo objetivamente válidō ỳ estrictamente científico, he aquí el objeto de la ciencia natural Es E Preciso tener presente que bajo ciencia natural, Husserl comprende también a la psicología, por cuanto la naturaleza, en sentido amplio, es unidad psicofísica. En efecto, lo psíqico no es, al igual que lo físico, algo que pueda subsistir en sí y por sí. Lo psíquico, por lo demás en muy diversos sentidos, se da como yo o como vivencia del yo; y, lo que es decisivo, en la experiencia se muestra siempre inseparablemente unido a algo físico que llamamos cuerpo. "Investigar científicamente este algo psí-

(1) Nicolai Hartmann, en su esfuerzo brillante por restituír a la ontología el rango que le corresponde dentro de las dísciplinas filosófieas, subraya el hecho de que todas las ciencias naturales presuponen las categorías naturales de espacio, tiempo, materia, movimiento. Lo que sean propiamente estas nociones, he aquí una determinación que ha de llevar a cabo la metafísica. Ce. Nicolai Hartmann, Zur Grundlegund der Ontologie. Berlin, 1935. 
quico en sus conexiones naturales psicofísicas, determinarlo de modo objetivamente válido, descubrir las leyes que rigen su formación, su transformación, su devenir - he aquí la tarea de la Psicología. Toda determinación sobre lo psíquico es pues eo ipso una determinación física, porque en 10 psíquico está dada siempre una significación física".

La cuestión es ahora complementaria de aquélla que había sido abordada en los Prolegómenos. Es preciso demostrar, ahora, que la ciencia natural física no puede ser filosofía en sentido específico y que no p uede, por lo tanto, servir como fundamento a la filosofía; y, luego, que los fundamentos válidos de la metafísica no pueden ser sino fundamentos de carácter filosófico. Si se logra demostrar lo anterior, quedará demostrada simultáneamente la imposibilidad en que se halla la Psicología para aportar fundamentos a la filosofía, y, también, el carácter no filosófico de esta disciplina "natural".

Como queda dicho, las ciencias naturales son ingenuas por cuanto tonansu punto de partida en la experiencia para terminar siempre en la experiencia A este respecto, es rotunda la frase con que comienzan las Ideas: "El conocimiento natural surge con la experiencia y permanece en la experiencia" ( I ). La ciencia natural ofrece, sin duda, métodos en los cuales se manifiesta crítica en grado sumo. Pero al lado de esta crítica, es imprescindible emprender otra, que, sin vulnerar la legitimidad que dentro de su dominio asiste a aquélla, plantee el problema de la experiencia en general y el del pensamiento empírico-científico. He aquí dos problemas, destacados de una serie más numerosa, propios de la teoría del conocimiento y que hasta ahora no han podido ser resueltos con claridad y distinción científicas.

(1) Husserl, Ideen zu einer reinen Phänomenologie und phänomenologischen Philosophic. Halle, 1928. 
La teoría del conocimiento pretende investigar el problema de las relaciones entre conciencia y ser. Pero el ser, según la dirección trascendental de la fenomenología, sólo puede ser tomado en consideración en el momento mismo de su relación con la conciencia, como correlato de la conciencia, como algo "mentado" por la conciencia (es decir, como algo percibido, recordado, identificada, sospechado, temido, angustiado, amado, etc. etc.). Lo que significa que la investigación debe orientarse hacia un conocimiento científico esencial de la conciencia, hacia aquello que la conciencia "es" esenciaimente a través de todas sus formas diferenciables; pero, al mismo tiempo, hacia aquello que "significa", así como hacia los diferentes modos mediante los cuales mienta lo objetivo. Examinemos con algún detenimiento esta cuestión nuclear.

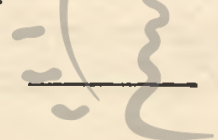

Buscamos una filosofía como ciencia rigurosa; en verdad, nuestro propósito se orienta hacia una prima philosophia, comprensiva, "tambiên, del concepto de ciencia rigurosa en general. La rigurosidad sólo podrá ser obtenida a través de conocimientos evidentes, apodícticos; la apodicticidad ha de ser para nosotros la categorí lógica sustitutiva de las nociones psicológicas de "claridad y distinción" (clarae et distinctae perceptiones) que operaban en Descartes. Acordemos nuestro procedimiento a nuestro propósito, y pongamos, en la base de nuestro indagar, conocimientos de evidencia apodíctica, esto es, un juicio en el cual la cosa no sea meramente "apuntada" de modo lontano e inadecuacio, sino presentada ella misma a la conciencia inmanente. Unicamente de este modo, renunciando a admitir como váuido todo juicio que no tenga respaldo apodíctico en la evidencia 
adecuada, podremos obtener "un orden de conocimientos anteriores en sí, relacionados con otros, en sí posteriores" (Méditations cartesiénnes, § 4).

Las Meditaciones han de servir de modelo en este punto decisivo. De acuerdo con nuestro propósito, debemos, a la manera de Descartes, indagar cuáles son las verdades primeras que deben y pueden sostener el edificio de la ciencia universal. Sabidas son las razones por las cuales Descartes propugnaba un punto de partida radical para la filosofía; debemos agregar que este radicalismo del punto de partida debe consultar sobre todo, y en priner lugar, el fundamento racional de las ciencias, y no presuponer que la noción de ciencia rigurosa se confunde con las ciencias real : históricamente existentes. Descartes había incurrido en el error de admitir una ciencia determinada (la matemática) como modelo de conocimiento evidente. Dejemos de lado, pongamos entre paréntesis toda ciencia, incluso la matemática.

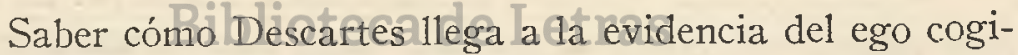
1.o, es "ejercicióo de hiñosinfilosóficos"so Seguida la meditación ,y realizada la epoké en élla propugnada, se abre, incontrovertible, la evidencia apodictica del sum cogitans. Sin embargo, Descartes incurrió aquí en una nueva inconsecuencia con respecto a su empeño radical. Si nos preguntamos qué yo puso Descartes en la base de todo conocimiento, hemos de reconocer que el yo cartesiano tenía un carácter puramente psicológico, patente en su identificación mens sive animus sive intellectus. Pero debemos avanzar todavía, y poner, como ser real que es, entre paréntesis también a la córiencia psicológica, es decir, a la conciencia del mundo real y empírico. Reduzcamos pues la conciencia psicológica.

Aqtí se inserta la noción de intencionalidad. Yo pienso equivale a yo pienso en (ego cogito cogitatum). Con lo cual, 
y como residuo de la reducción trascendental, surge la conciencia pura, de estructura bipolar, por cuanto, por uno de sus lados, apunta al objeto y por el otro, al sujeto. Mirada desde el punto de vista de la subjetividad trascendental, la conciencia pura se nos muestra nó como vivencia constante y permanente, nó como "idea fija", sino como algo necesario por principio, puesto que permanece absolutamente idéntica en todos los cambios de la conciencia psicológica y porque de ninguna manera puede ser considerada como trozo real o momento de las vivencias temporales no inmanentes (de la subjetividad empírica). Esta conciencia trascendental proyecta su mirada a través de todo cogito actual, a lo objetivo. Por lo mismo, el yo puro debe hallarse en relación o conexión con las vivencias. Lo que quiere decir que, mirada desde el lado del objeto, es válida, con respecto a la conciencia trascendental, el principio kantiano: "El yo pienso debe poder acompañar a todas mis representaciones" (Ideen, § 57).

Así pues hemosiganado ya tun fundamento absoluto de conocimiento, un primeriprincipio apodíctico que no puede ser tocado por ningún ataque naturalista. Cómo desarro1la Husserl la teoría fenomenológica del conocimiento, partiendo de este "punto de partida indubitable", es tema que no nos compete desarrollar aquí. Dados los límites del presente trabajo, basta subrayar el principio de que la conciencia trascendental es, según Husserl, el fundamento, la posibilidad de todo conocimiento. Pues todo objeto, esto es, todo "algo" susceptible de predicación racional, debe manifestarse en el conocimiento, darse a la conciencia misma: todo conocimiento significa un entrar en relación un objeto y una conciencia cognoscente. He aquí el leit motif de toda la fenomenología trascendental. En una etapa posterior a las 
Ideas, Husserl parece haber virado hacia una concepción más y más kantiana. "Todo ser se constituye en la subjetividad de la conciencia", "nada es para mí sino en un acto actual o potencial de la conciencia", "yo soy el fundamento intencional de mi mundo", he aquí algunos principios contenidos en la Lógica formal y trascendental ( I). La fenomenología en sentido estricto ha de considerar pues como tema capital, la investigación de la conciencia trascendental. Conciencia trascendental que, repetimos, es obtenida como evidencia última, como lo "absoluto" que la filosofía de todos los tiempos ha buscado y que está llamado a dar una base racional última a toda ciencia y a toda filosofía. Este absoluto no designa por cierto ningún ser, sino el fundamento último que hace factible el conocimiento de todo ser posible. E. Fink, en una exposicion de la filosofía de Husserl a la que el propio filósofo concedió su venia, aseguraba que la cuestión fundamental de la fenomenología es el problema del origen del mundo (Kantstudien, Band $3^{8}$ ).

\section{Biblioteca de Letras "Jorge Puccinelli Converso»}

Todo objeto susceptible de predicación racional que deba ser aprehendido en un conocimiento científico, debe manifestarse a la conciencia. Todos los actos de conocimiento que corresponden especialmente a las diferentes categorías de objetos, se agrupan en modos de conciencia, en grupos de funciones de conocimiento. Aquellas categorías de objetos no podrán ser consideradas sino como contrafiguras intencionales de la conciencia; por lo tanto, deberán estudiarse, en primer lugar, en su manera de darse, es decir, en sus relaciones retrospectivas con las formas de conciencia del ob-

(1) Husserl, Formale und transzendentale Logik. Halle, 1929. 
jeto que a cada una de ellas pertenece; $y$, en segundo lugar, en su qué esencial, en su estructura ontológica y, por último, en las relaciones esenciales de las categorías de objetos (como contrafiguras intencionales de la conciencia, es decir, en su significación para la conciencia) entre sí.

Así, pues, qué sea la objetividad, qué se muestre como existente y como existente así en el conocimiento, he aquí algo que debe hacerse evidente y comprensible sin resíduos, puramente de la conciencia misma. Es preciso, luego, estudiar la conciencia en su totalidad, pues cada una de las formas de la conciencia constituye una posible función de conocimiento. Pero este análisis esencial de la conciencia incluye el de los modos fundamentales de las objetividades, pues, como queda dicho, las objetividades puestas entre paréntesis en virtud del método de la reducción trascendental, tornan a encontrarse en la subjetividad pura como contrafiguras intencionales.

Los anteriores análisis muestran el contenido propio de la fenomenología. Ciencia de cuya extensión, según frase de Husserl, los contemporáneos no tiênen todavía una idea cabal, y que está llamáda a erigirse en disciplina filosófica fundamental mediante el trabajo severo de largas generaciones de investigadores. El dominio cerrado de la fenomenología está dado, como se ve, por la conciencia. También la psicología estudia, y desde su punto de vista legítimamente, la conciencia. El punto de vista, el objeto de referencia legítimo de la psicología, es la conciencia empírica, ente que existe incrustado en la ligazón establecida por las conexiones naturales. La fenomenología, en cambio, halla su dominio de investigación en la conciencia pura, en la conciencia en la actitud fenomenológica.

En opinión de Husserl, la psicología, al igual que toda ciencia natural, no es, ni puede pretender serlo, filosofía. 
Toda teoría del conocimiento psicologista falsea el sentido legítimo de la problemática gnoseológica. Por lo tanto, es preciso guardarse de "naturalizar" la conciencia pura y mantenerla estrictamente diferenciada de la meramente empírica.

La psicología no puede pretender ser la única ciencia de lo psíquico, no es lícito su intento de comprender en su dominio el sentido total de lo psíquico. Quedará siempre fuera del dominio de la psicología el análisis de la conciencia misma. Los pocos psicólogos que en el siglo último emprendieron este análisis inmanente, esencial, en la forma de análisis analítico-descriptivos de las vivencias intencionales, fueron tachados de escolásticos. Husserl hace notar que la voz de orden contra estos escolásticos fué: volvamos a las cosas mismas, interroguemos a la experiencia, pues este es el único medio gracias al cual podemos conquistar, para nuestros principios, un defecho racional y dotar de sentido a nuestras palabras. Muy bien. Pero, dice Husserl, ¿cuáles son aquí las cosas mismas? ¿Acaso la experiencia primaria de lo psíquico no reside en el sujeto mismo, al margen de toda psicología interpretativa? ¿Acaso esta experiencia primaria no constituye una "cosa misma"? Por lo demás, ¿cómo puede ser tachado de escolástico el análisis fenomenológico, que no deriva ningún juicio de conceptos meramente verbales y que preconiza la exposición en la intuición de los conceptos de la experiencia (Exposición que eleva la experiencia nastural a la experiencia eidética, a la experiencia fenomenológica. Pues el análisis fenomenológico, por extraño que pueda sonar a los oídos del naturalista esta aseveración, no es absolutamente "experiencia"). 
El naturalista, en efecto, afirma que todo concepto toma el fundamento legítimo de su uso posible, de la nuda experiencia, es decir, de todo aquello que signifique una percepción o un recuerdo real. De Locke arranca la concepción aún imperante de que toda representación conceptual "proviene" de experiencias anteriores. El psicólogo naturalista usa las palabras percepción, recuerdo, angustia, etc. La consideración es, para él, trascendente, por cuanto mienta hechos desligados y apartados de la conciencia cognoscente y de la conciencia misma en que trascurren. Sin embargo ¡qué plenitud de componentes inmanentes hay en estas palabras, es decir, componentes intuíbles en el acto mismo del experimentar, y que pueden ser alcanzados únicamente en virtud del regreso fenomenológico! Tan solo este regreso permite elaborar metódicamente, describir y determinar esencialmente estos conceptos. La psicología no nos dona sino de modo "confuso", y en experiencia "vaga", estos hechos. Pero cómo sea esencialmente el ser, cómo sea dêteriminable dè modo objetivamente válido, he aquí un grupo de problemas eidéticos que únicamente la ienomenología puede desarrollar.

Unicamente, dice Husserl, el mundo corporal, el mundo espacio-temporal es naturaleza en sentido estricto. El ser psíquico es naturaleza tan solo en un segundo sentido. Esta diferencia determina que los métodos de las ciencias naturales y el que debe ser llevado a cabo en el análisis de la conciencia,. sean radicalmente distintos. El ser corporal es por principio aprehensible como individualmente idéntico a través de una pluralidad de experiencias directas - de percepciones,- es decir, como unidad intersubjetiva. Las cosas 
son precisamente aquello que son en cuanto están contenidas en la unidad espacio-temporal; lo que permite a cada cosa destacarse como identidad individual es, justamente, su relación causal o su enlazamiento temporal con otras cosas. Las cosas son portadoras de "propiedades reales"; pero toda propiedad corporal-real es causal. Todo ser corporal está bajo las leyes de sus cambios posibles, leyes que conciernen a lo idéntico de la cosa, a su conexión unitaria, real y posible, con la naturaleza una. El término "propiedades reales" designa pues las posibilidacies de mutación de algo idéntico, posibilidades que están causalmente predeterminadas. Qué sea esto idéntico, he aquí algo que, en el senticlo de la ciencia natural, sólo puede ser determinado por medio de estas leyes. Las cosas son dadas, empero, como unidades de experiencia inmediata, como unidades de fenómenos sensiblemente diversos.

Dirijamos ahora nuestra consideración a lo psíquico. Atengámonos únicamente a los "fenómenos psíquicos", en los cuales la nueva psicología ve su objeto propio de investigación. Ahora bien. Es innegable que en cada aprehensión de lo psíquico no esta dada una objetividad en el mismo sentido que en la percepción de lo corporal. "El ser psíquico, el ser como "fenómeno" no es, en principio, una unidad que fuera aprehensible en múltiples percepciones concretas como individualmente idéntico, ni aún para el propio sujeto autopercipiente". Lo que equivale a decir que en la esfera de lo písquico, ser (naturaleza) y fenómeno se confunden, puesto que el ser aparece en los fenómenos, se da en los fenómenos misnos sin aue pueda diferenciársele de éllos. Un fenómeno de la esfera psíquica no es ninguna unidad sustancial en el mismo sentido que lo es una objetividad natural ("Una cosa sensible es aquello que es y permanece para siempre en su identidad"). Es un contrasentido, por lo 
tanto, naturalizar aquello cuya esencia excluye el ser como naturaleza. Así, pues, hay, propiamente hablando, sólo una naturaleza, la que se manifiesta en las cosas corporales.

La naturaleza es en cierto modo eterna. Aquello que la cosa natural es, puede determinarse de modo objetivamente válido y puede ser ratificado en una serie, en principio sin término, de experiencias. Por el contrario, un fenómeno psíquico deviene, no persevera como ser idéntico que pudiera determinarse de modo objetivo en el sentido de la ciencia natural (que fuera, por ejemplo, objetivamente divisible en componentes, o "analizable" en el sentido de determinar sus causas y efectos).

Lo que sea el ser psíquico no lo puede decir la experiencia, entendida ésta como experiencia natural. Para decirlo con toda claridad, $\mathrm{V}$ a fin de evitar todo malentendido: lo psíquico no es experimentado como fenómeno; lo psíquico es "vivencia", vivencia intuída en la reflexión y que aparece como una fluencia absoluta-un ahora que inmediatamente se hunde en un antes- En lo psíquico, la fluencia de las vivencias está, por decirlo asíntransitada por una línea intencional que a todos los comprende, a saber, la línea doblemente ilimitado del "tiempo" inmanente - tiempo sin comienzo y sin fin que no puede ser medido por ningún reloj- ( I . Como vemos, no aparece aquí todavía completamente clara la concepción de la conciencia pura trascendendental.

Ahora bien. Toda vivencia "tiene" una "significación" y "mienta" algo "objetivo"-que puede ser ficción o realidad-. Cuando en la fluencia inmanente de lo psíquico, la visión, támbién inmanente, de la reflexión adviene a una

(1) Edmund Husserl Vorlesungen zur Phanomenologie des Inneren Zeitbewusstseins. Halle, 1928. 
sintesis con la experiencia sensible, entran en relación un fenómeno intuído (el qué eidético) y la cosa corporal experimentada. Esta cosa corporal (la noema) es describible como algo "objetivo inmanente", como "lo mentado como tal" en esta o aquella forma de conciencia (la noesis). La investigación "pura inmanente" de lo psíqico es pues posible, en contraposición a la investigación psicofísica, la que, desde luego, tiene sus derechos legítimos.

Si lo psíquico inmanente no es naturaleza, sino lo contrario de naturaleza ¿qué es lo que investigamos en él como su ser? Si no es determinable en identidad "objetiva" como unidad sustancial cuya aprehensión puede siempre reiterarse, y carece de propiedades reales que puedan determinarse y ratificarse en el sentido de las ciencias de la experiencia; si no se le puede destacar de su fluencia eterna; y si es inapto para.convertirse en objeto de validez intersubjetiva - ¿qué es lo que podemos aprehender y determinar en él como unidad objetiva? ${ }^{\mathrm{N}}$ N se olvide de ninguna manera que permanecemos en la esfera fenomenológica pura y que dejamos fuera de consideración toda referencia al cuerpo y a la naturaleza. La respuesta a la pregunta anterior afirma que si bien los fenómenos (psíquicos) como tales no son naturaleza, tienen en cambio una esencia aprehensible de modo adecuado en el contenido de una intuición inmediata. Todos los enunciados que describen a los fenómenos mediante conceptos directos, lo hacen, en tanto que son válidos, mediante, conceptos esenciales que deben poder resolverse en la intuición esencial.

La actitud natural es la que nos hace incapaces para desviar nuestra mirada de la naturaleza y la que nos empu- 


\section{- $447-$}

ja a situarnos en la actitud psicofísica y nó en la pura (en investigación intuitiva); esta es la actitud que ha imepdido hasta ahora se abra camino a una ciencia que por un lado es una psicología plenamente científica, y, de otro, el campo de una legítima crítica de la razón. El naturalismo nos dificulta la visión de las "esencias", de las "ideas", el aprehenderlas en la validez que les es propia según su peculiaridad (en vez de naturalizarlas absurdamente). La intuición esencial no encubre ninguna dificultad o secreto "místico", pues es una percepción. Cuando nos es dado en intuición plena el "color", entonces lo dado es una "esencia"; y cuando, también en la actitud de la intuición pura, discurre nuestra visión inmanente de percepción en percepción, aprehendemos intuitivamente la esencia de la percepción. "Hasta donde alcanza la intuición, el tener intuitivo de la conciencia, hasta allí alcanza la posibilidad de una "ideación" (ideación era el término empleado por Husserl en las Investigaciones Lógicas) correspondiente o intuición esencial". En tanto que la intuiciónes resnatintuición pura, da esencia aprehendida lo es de modo adecuado $\mathrm{Y}_{\mathrm{i}}$ se presenta a aquélla como algo absoluto.

Que la esencia aprehendida en la intuición esencial puede ser fijada en conceptos firmes; y que con ello otorgue la posibilidad de enunciar principios absolutamente válidos y objetivos - he aquí algo comprensible sin más para todo aquel que carezca de prejuicios. Estas esencias, absolutamente diferenciables y fijables, no son únicamente aquellas que corresponden a los "contenidos" sensibles, sino también, y no ménos, aquellas que corresponden a lo psíquico en sentido estricto, a todos los "actos" y estados del yo (ejemplos: percepción, fantasía, recuerdo, juicio, sentimiento, angustia, asco, etc. etc.). Toda vivencia, (como perecpción o o voluntád) constituye un inmenso campo de análisis fenome- 
nológicos, de "análisis de conciencia", es decir, un campo para investigaciones esenciales. He aquí un dominio, en opinión de Husserl, cuya vastedad sólo puede ser comparada a. la de la ciencia natural. Dominio llamado a establecer la conciencia pura como fundamento absoluto del conocimiento eidético. Superadas así las dos tesis naturalistas (naturalización de la conciencia, naturalización de las ideas), se abre el camino al trabajo empeñoso y duradero de la filosofía como ciencia rigurosa.

Carlos Cueto Fiernandini.

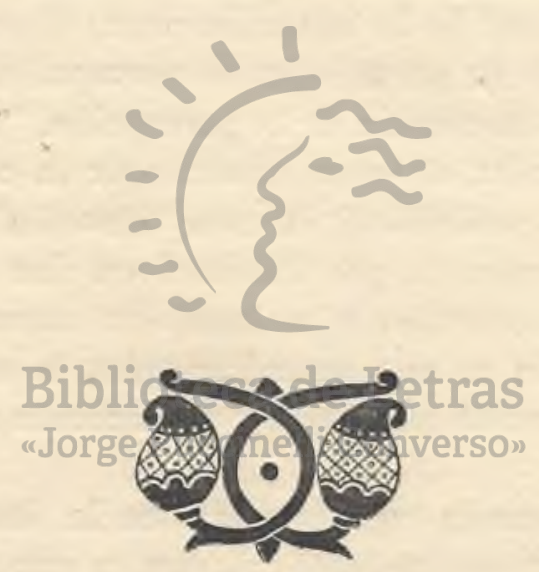

